\title{
The Effect of Theraband Exercises on Motor Performance and Swimming Degree of Young Swimmers
}

\author{
Zait Burak AKTUĞ ${ }^{1}$, Şeyda Nur VURAL², Serkan İBIŞ¹ \\ ${ }^{1}$ Niğde Ömer Halisdemir University, School of Physical Education and Sports, Nigde, Turkey \\ ${ }^{2}$ Niğde Ömer Halisdemir University, Social Scince Institute, School of Physical Education and Sports, Graduate Student. Niğde, Turkey \\ Address Correspondence to ZB AKTUĞ, e-mail: zaitburak@gmail.com
}

\begin{abstract}
Different training methods are used to improve children's swimming degrees and motor performance. There are a limited number of studies examining the effects of therabands, which are portable and available everywhere, on swimmers. The aim of this study was to investigate the effect of 8 weeks of theraband exercises on motor performance and $50 \mathrm{~m}$ freestyle swimming degree. 45 voluntary children (male $=27$, female $=18$ ) participated in the study. The children were divided into three groups; control group (CG), swimming group (SG) and theraband group (TG), each consisting of 15 people. SG did swimming training only three times a week for eight weeks. In addition to swimming exercises, TG did theraband exercises consisting of 8 movements to the lower and upper extremities. The motor performances of the swimmers were determined by the Dordel Koch Test (DKT), which consists of 7 subtests, and swimming degrees were determined by the stopwatch. Wilcoxon Signed Ranks Test was used to determine the difference between pre-tests and post-tests following 8-weeks of exercise. According to the results, it was determined that in SG, $50 \mathrm{~m}$ swimming degree and DKTsideward jump performances increased in the posttest, while in TG, $50 \mathrm{~m}$ swimming degree, DKTsideward jump, DKTflexibility, DKT standing long jump, DKTsit-up, DKTbalance and DKTpush-up performances improved significantly in the post-test $(\mathrm{p}<0.05)$. As a result, in addition to in-water training to improve swimming performance, it can be stated that land training has positive effects on swimming degrees and theraband exercises increase motor performance. It can be recommended that swimming coaches incorporate theraband exercises into the content of training programs to improve both swimming and motor performance of children.
\end{abstract}

Key words: Swimmer, motor performance, DKT

\section{INTRODUCTION}

Motor performance, which is defined as the act of performing a movement skill, (7) is an important indicator that shows the healthy status and technical success of children $(2,21,27)$. Increasing the level of physical activity and doing a sport branch have positive effects on motor performance (6). One of these sports branches is swimming.

Swimming is a sports branch which is a combination of several factors such as high-level muscle strength, technical skills, rhythm requiring coordination, speed, explosive strenght and correct technique $(8,18,29)$. When the factors affecting the performance in swimming and the changes that the swimmers show according to age groups, it is seen that muscle strength is extremely effective (28). In swimming, strength is the most important factor that enables to move forward in water (11). Swimmers need to develop muscle strength in order to increase their swimming speed (16). In addition to in-water exercises, land trainings are also applied to improve strength and other motoric features required in swimming $(8,23)$. In land training, different materials and training methods are used to increase the strength and swimming performance of swimmers. Some coaches use resistance machines to increase the strength performance of swimmers, while others prefer body weight, medicine ball, and core exercises (22). Recently, theraband (resistance rubber) exercises have been used extensively to increase muscle strength and endurance $(12,17)$.

It is a well-known fact that that the exercises performed with theraband increase the strength and mass of the muscles to which they are applied (20). Guex et al. (10) found that maximal muscle strength, muscle endurance can be improved and muscle hypertrophy can be achieved by using theraband. Therabands can be used as an alternative to other strength training sessions since they can be used in all age groups due to their low cost and extensive availability as well as operating more than one region at the same time; (20) moreover, they can be applied anywhere without any difficulties (13). 
In the light of this knowledge, the aim of this study was to investigate the effects of 8-weeks theraband exercises on swimmer children on motor performance and swimming degree. Our hypothesis is that theraband exercises performed by child swimmers will have positive effects on their motor performance and swimming degree.

\section{MATERIAL AND METHOD}

Forty-five voluntary children (male $=27$, female $=18$ ) with a mean age of $11.67 \pm 1.41$ participated in the study. The children were divided into three goups; the children in the control group (CG) did not do any exercises, the children in the swimming group (SG) did swimming 3 days a week for 8 weeks, and along with swimming exercises, the children in the theraband group (TG) did exercises related to the lower and upper extremities 3 days a week for 8 weeks. Children's height were measured using a standard steel stadiometer, with a barefoot accuracy of $0.1 \mathrm{~cm}$, and with no metal on the Tanita BC-418 Segmental Body Analysis System (Tanita Corporation, Tokyo, Japan). The BMI of children was calculated using the formula [body weight $(\mathrm{kg})$ / height (m2)]. Children's sit-up, push-up, balance, standing long jump, flexibility, sideward jump and 6 min running motor performances were determined by Dordel Koch Test and $50 \mathrm{~m}$ freestyle swimming was determined by stopwatch. Children with TG were given theraband exercise, which consisted of 8 movements 3 times a week for 8 weeks and each session lasted approximately 35-40 minutes.

\section{Dordel Koch Test}

The Dordel Koch Test (4), developed by Dordel and Koch in 2004, is specifically designed for the determination of motor performance and basic functions of children and adolescents aged 6-16 years. The Dordel-Koch Test consists of 7 different tests. While 6 of them are performed individually at the established stations (sideward jump, balance, standing long jump, sit-up, push-ups flexibility), the 6-minute running test which is the last test is performed in a group. The best degree of measurement is included in the study.

DKTsideward jump test; the child jumped over the rope which was folded four times and fixed at the ground in 15 seconds at the highest speed with double feet and without touching the rope. The test was performed twice and the average of two tests was included in the study.
DKTflexibility test; it is a test that measures the flexibility of the waist and especially the hamstring muscles. The soles of the children are measured on the base of the flexibility table, with the knees reaching straight to the last point they can reach with their hands. The point at which the sole of the foot rests is zero (0), the side on which the feet lie is positive (+), and the side of the calf is negative (-). The test was performed twice and the best value was recorded in $\mathrm{cm}$.

DKTstanding long jump test; the child was taken from the back of the line determined as zero by taking strenght from the arms, the legs adjacent to the farthest point can be reached as a double leg jump. The degree at the end point of the child's heel was recorded in $\mathrm{cm} .2$ trials were granted and the best rating was included in the study.

DKTsit-up test; the child was measured with the hands behind the head, elbows to the side, with the leg bent from the knees and the body closer to the knees. Each full movement performed within 40 seconds was accepted as 1 and recorded as pieces.

DKTbalance test; the children were measured as one leg standing on the rope fixed to the ground in pairs for 60 seconds. The number of contact of the foot which is not on the rope to the ground was recorded in units.

DKTpush-up test; the children started the pushup test with their hands on the hips, when the face is down. With the start of the time, the body was lifted by pushing the hands under the untied shoulders and the movement was completed by returning to the starting position after one hand touched the other hand. The number of push-ups that the child could do in 40 seconds was recorded in units.

DKT6-min running test; the children ran around the area of the volleyball court $(54 \mathrm{~m})$ as fast as possible for 6 minutes. The children completed this distance in 6 minutes by running or walking when they felt tired. The total distance was recorded in metre.

Each of the sub-dimensions of DKT was scored and evaluated separately, and no general score and assessment were conducted in DKT. DKT subdimension performances were indicated by scores from 1 to $6: 1$ = very good, 2 = good, 3 = moderate, 4 $=$ adequate, $5=$ poor, $6=$ very poor. 
$50 \mathrm{~m}$ Freestyle Swimming Performance Measurement

The $50 \mathrm{~m}$ freestyle swimming performances of the swimmers were measured with a hand stopwatch (Casio, Japan) measuring 0.01 seconds. The swimmers were warmed for 5 minutes on land and 10 minutes in water. $50 \mathrm{~m}$ freestyle swimming test started with ready-exit command by pushing the wall of the pool with its feet and when the $50 \mathrm{~m}$ distance was completed, the test was terminated. Two swimmers were taken from each swimmer and 30 minutes rest was given between 2 measurements. The best value was included in the study.

\section{Theraband Exercises}

The training program with theraband consists of 8 exercises to improve upper and lower extremity strength. These movements are: a) sit-up, b) front raise, c) squat and bench press, d) lut pull down back, e) lateral raise, f) leg press, g) scapular retraction, h) lunge. All movements were performed

\section{INTERPRETATION OF ANALYSIS AND FINDINGS}

Table 1. Physical feature of the groups

\begin{tabular}{lcccc}
\hline & & Height & Weight & BMI \\
\cline { 2 - 4 } & & $\bar{x} \pm$ Sd & $\bar{x} \pm$ Sd & $\bar{x} \pm$ Sd \\
\hline Control Group & Pre Test & $1.54 \pm 0.05$ & $42.66 \pm 7.65$ & $17.84 \pm 2.43$ \\
\cline { 2 - 5 } & Post Test & $1.57 \pm 0.05$ & $42.33 \pm 8.35$ & $17.03 \pm 3.01$ \\
\hline Swimming Group & Pre Test & $1.51 \pm 0.11$ & $45.46 \pm 11.08$ & $19.71 \pm 3.63$ \\
& Post Test & $1.55 \pm 0.11$ & $46.6 \pm 9.88$ & $19.28 \pm 3.25$ \\
\hline Theraband Group & Pre Test & $1.55 \pm 0.11$ & $46.73 \pm 12.27$ & $19 \pm 3.55$ \\
& Post Test & $1.59 \pm 0.01$ & $47.4 \pm 12.3$ & $18 \pm 3.38$ \\
\hline
\end{tabular}

\begin{tabular}{|c|c|c|c|c|c|c|c|}
\hline & & \multicolumn{2}{|c|}{ Control Group } & \multicolumn{2}{|c|}{ Swimming Group } & \multicolumn{2}{|c|}{ Theraband Group } \\
\hline & & $\bar{x} \pm S \mathrm{~d}$ & $\mathrm{p}$ & $\bar{x} \pm S d$ & $\mathrm{p}$ & $\bar{x} \pm S d$ & $p$ \\
\hline \multirow[t]{2}{*}{ DKTsideward jump } & Pre Test & $3.13 \pm 1.06$ & 0.13 & $5.60 \pm 1.12$ & $0.00^{*}$ & $5.53 \pm 0.83$ & $0.00^{*}$ \\
\hline & Post Test & $2.80 \pm 1.08$ & & $3.53 \pm 1.68$ & & $1.93 \pm 0.79$ & \\
\hline \multirow[t]{2}{*}{ DKTflexibility } & Pre Test & $3.40 \pm 0.63$ & $0.02^{*}$ & $380 \pm 1.26$ & 1.00 & $3.06 \pm 0.79$ & $0.02^{*}$ \\
\hline & Post Test & $2.80 \pm 0.77$ & & $3.80 \pm 1.2$ & & $2.27 \pm 0.70$ & \\
\hline \multirow[t]{2}{*}{ DKT standing long jump } & Pre Test & $4.33 \pm 1.04$ & 0.48 & $4.20 \pm 0.94$ & 0.058 & $3.66 \pm 1.17$ & $0.03^{*}$ \\
\hline & Post Test & $4.47 \pm 0.91$ & & $3.80 \pm 1.14$ & & $2.60 \pm 0.28$ & \\
\hline \multirow[t]{2}{*}{ DKTsit-up } & Pre Test & $3.8 \pm 1.08$ & 0.41 & $3.40 \pm 0.82$ & 0.15 & $3.53 \pm 0.91$ & $0.00^{*}$ \\
\hline & Post Test & $3.93 \pm 0.96$ & & $3.27 \pm 0.7$ & & $2.20 \pm 0.56$ & \\
\hline \multirow[t]{2}{*}{ DKTbalance } & Pre Test & $4.93 \pm 1.16$ & 0.38 & $4.66 \pm 1.11$ & 0.49 & $4.33 \pm 0.72$ & $0.00^{*}$ \\
\hline & Post Test & $5.27 \pm 0.59$ & & $4.80 \pm 1.2$ & & $2.60 \pm 1.12$ & \\
\hline \multirow[t]{2}{*}{ DKTpush-up } & Pre Test & $2.33 \pm 0.97$ & 0.10 & $1.73 \pm 0.88$ & 0.65 & $3.20 \pm 1.14$ & $0.00^{*}$ \\
\hline & Post Test & $1.93 \pm 0.96$ & & $1.80 \pm 0.77$ & & $1.67 \pm 0.48$ & \\
\hline \multirow[t]{2}{*}{ DKT6 min running } & Pre Test & $5.66 \pm 0.48$ & 0.08 & $3.33 \pm 0.97$ & 0.81 & $3.66 \pm 1.04$ & 0.29 \\
\hline & Post Test & $5.47 \pm 0.51$ & & $3.53 \pm 1.64$ & & $3.13 \pm 1.12$ & \\
\hline
\end{tabular}

3 days a week for 8 weeks. The children were given rest 1 minute between each set and 2 minutes between each new exercise. Therabands have different colors and the tire resistance of each color changes. The blue colored therabands, which are the intermediate level, were preferred considering the educational status and the children who participated in the study. The starting and ending positions of the movements are shown in the following figures. Set and in-set numbers of the exercise program are as follows: 1 st and 2 nd week $10 \times 2$, 3rd and 4 th week $10 \times 3,5$ th and 6 th week $12 \times 3,7$ th and 8 th week $15 \times 3$.

\section{Statistical Analysis}

SPSS 24 package program was used for data analysis. The difference between pre-post tests and sub-dimensions of DKT the groups was determined by Wilcoxon Signed Ranks Test, which is one of the nonparametric tests. Significance level was accepted as $\mathrm{p}<0.05$. 
When the table is examined, it is seen that while the DKTflexibility performance of the control group increased, the DKTsideward jump of the swimming group increased statisticaly significantly in the post-test. In addition, it was found that theraband group had statistically significant improvements in the performances of DKTsideward jump, DKTflexibility, DKTstanding long jump, DKTsirt-up, DKTbalance and DKTpush-up test.

Table 3. Comparison of pre-test and post-test of $50 \mathrm{~m}$ freestyle swimming degrees of the groups

\begin{tabular}{|c|c|c|c|c|c|c|c|}
\hline \multirow{4}{*}{$50 \mathrm{~m}$ Swimming } & & \multicolumn{2}{|c|}{ Control Group } & \multicolumn{2}{|c|}{ Swimming Group } & \multicolumn{2}{|c|}{ Theraband Group } \\
\hline & & $\bar{x} \pm S d$ & $\mathrm{p}$ & $\bar{x} \pm S d$ & $\mathrm{p}$ & $\bar{x} \pm S d$ & $\mathrm{p}$ \\
\hline & Pre Test & & & $44.48 \pm 6.52$ & 0.00 & $40.51 \pm 7.00$ & 0.00 \\
\hline & Post Test & & & $42.71 \pm 6.29$ & & $37.48 \pm 6.91$ & \\
\hline
\end{tabular}

$\mathrm{p}<0,05$

As it is clearly seen in the table that it was found that swimming degrees of both swimming and theraband group improved statistically significant in the posttest.

\section{CONCLUSION AND EVALUATION}

It is necessary to apply technical exercises in order to form the basis of high-level training in swimming and to apply strength training in order to show high performance in competitions (23). Strength training is always necessary to improve the performance of swimmers and ensure continued success in competitions (5) and should be planned according to the strengths and weaknesses of the athletes (19).

In the study, it was determined that 8-week theraband exercises increased motor performance (DKTsideward jump, DKTflexibility, DKTstanding long jump, DKTsit-up, DKTbalance and DKTpushup) and $50 \mathrm{~m}$ freestyle swimming performance, but no effect on DKT6-minute running performance was found.

In the strength training program of swimmers, land and water trainings are applied together. The aim is to transfer the strenght gained by the swimmer to the water. For land training, including strength and flexibility training, swimmers are required to spend for 3 hours or more per week (16).

There are a number of studies in the literature examining the effects of different land training on swimming performance and motor performance. Biyıklı (1) stated that the 10 -week core training applied to 11-13 age group swimmers with improved speed, vertical jump, balance, sit-up, right-left hand grip and flexibility performance, and stated that core training would contribute to the physical performance of children. In a similar study, Yapic1 et al. (29) investigated the effect of 6-week land and resistance training on lower extremity isokinetic strength values and swimming performance in 22 swimmers in the 13-16 age group. As a result of the study, it was determined that knee extensor and flexor muscle strength increased at 60 $\%$ s, $180 \%$ and $240 \%$ after 6 weeks of training and $25 \mathrm{~m}, 50 \mathrm{~m}$ and $100 \mathrm{~m}$ freestyle swimming degrees improved.

Yapic1 et al. (29) reported that land and resistance training for swimmers in this age group made a significant contribution to strength and swimming performance. In another study, Şenol and Gülmez (26) divided 21 child swimmers aged 13 into 3 groups as strength training with functional exercise band, strength training with their own body weight and swimming training only. As a result of the study, it was determined that the performances of push-ups, sit-ups, medicine ball throwing, vertical jump, leg strength, $50 \mathrm{~m}, 150 \mathrm{~m}$ and $200 \mathrm{~m}$ swimming performances of the strength training swimmers with functional exercise band increased statistically significantly. Karakuş et al. (14) reported that 12 weeks of swimming training increased leg, back and hand strength in the study, which included 14 children aged 7-9 years.

In a study conducted on students between the ages of 9 and 13, the swimmer group received a total of 60 training sessions per week for 12 weeks, including 4 swimming training sessions and 1 land training training. At the end of the program, there was a significant improvement in the $25 \mathrm{~m}$ freestyle swimming performance of both boys and girls (3). Santana (24) conducted a study on competitor male swimmers applied to the core training of young 
swimmers found that the increase in strength parameters.

Theraband training program was applied to increase the swimming and motor performances of the children who participated in our study. There are some studies with therabands in the literature. Selcuk and Karacan (25) at least two years of swimming training applied to boys aged $11-13$ years to determine the effects of theraband training swimming performance of children divided into two groups. The first group is the experimental group that performs theraband training in addition to swimming (swimming 2 days a week for 12 weeks, and strength training with theraband in addition to swimming for 3 days). The second group is the control group that only swims (5 days a week only swimming training). As a result of the study, it was determined that both the theraband group and the swimming group had better performance in the 25 $\mathrm{m}, 50 \mathrm{~m}, 100 \mathrm{~m}$ and $200 \mathrm{~m}$ swimming performances, yet theraband group had better performances in 25 $\mathrm{m}$ and 50 rather than swimming group. Selcuk and Karacan (25) interpreted this as the positive effect of theraband streght studies on short distance swimming performance. In another study, Gönener et al. (9) divided 20 adolescent children into swimming as a control group and theraband training group for at least 3 years. Theraband training group received 12 different theraband training sessions 3 times a week for 8 weeks. It was determined that theraband training is an effective method to improve swimming performance in swimmers between the ages of 13-15. In a similar study, Kilinc et al. (15) examined the effect of swimming exercise and theraband studies on dynamic and static balance in children aged 7-12 years who have been interested in swimming for at least 2 years and who regularly train swimming 5 days a week while dividing the whole participants into 3 groups. As a result of the study, it was determined that theraband group was more successful in balance performance.

The studies mentioned above support the findings of our study and show that land trainings have important contributions on motor and swimming performance. It can be said that the theraband training program used in our study can be used as an alternative to other strength training equipment and programs to improve the motor and swimming performance of children. As a result, it can be said that in order to improve the swimming performance of young swimmers, it is necessary to Turk ل Sport Exe 2019; 21(2):238-243 (4) 2019 Faculty of Sport Sciences, Selcuk University increase the motor performance and the motor performance can be provided by therabands which can be used everywhere, can operate many regions at the same time, and is easy to carry and cost effective.

\section{REFERENCES}

1. Bıyıklı T. 10 haftalık core antrenmanın 11-13 yaş arası kız yüzücülerde fiziksel performansa etkisi. Sportif Bakış: Spor ve Eğitim Bilimleri Dergisi, 2018; 5(2): 81-91.

2. Callewaert M, Boone J, Celie B, De Clercq D, Bourgois J. Indicators of sailing performance in youth dinghy sailing. European Journal of Sport Science, 2015; 15(3): 213-219.

3. Çelebi Ş. We Investigate Body Structural and Functional Properties in 9-13 Year Childeren Who Takes Swimming Training. Master Thesis. Erciyes University, Healt Sciences Institute, Kayseri: 2008.

4. Dordel S, Koch B. Basistest Zur Erfassung Der Motorischen Leistungsfähigkeit Von Kindern Und Jugendlichen [Test For the Assessment of Motor Performance of Children and Adolescent]. Deutsche Sporthochschule Köln, Germany: Cologne, 2004

5. Faigenbaum AD, Miliken LA, Loud RL, Burak BT, Doherty CL, Westcott WL. Comparison of 1 and 2 days per week of strength training in children. Research Quarterly for Exercise and Sport, 2002; 73(4): 416-424.

6. Fransen JJ, Pion J, Vandendriessche B, Vandorpe B, Vaeyens R, Lenoir M, Philippaerts RM. Differences in physical fitness and gross motor coordination in boys aged 6-12 years specializing in one versus sampling more than one sport. Journal of Sports Sciences, 2012; 30(4): 379-386.

7. Gallahue DL, Ozmun JC, Goodway J. Understanding Motor Development: Infants, Children, Adolescents, Adults. Boston: Mcgraw-Hill: 2006.

8. Garrido N, Marinho DA, Barbosa TM, Costa AM, Silva AJ, Perez-Turpin JA, Marques MC. Relationship between dryland strength, power variables and short sprint ostoperformance in young competitive swimmers. Offical Journal of the Area of Physical Education and Sport, 2010; 5(2): 240-249.

9. Gönener A, Gönener U, Yilmaz O, Horoz T, Demirci D. The effect of 8-week thera-band exercises on male swimmers' 100 $\mathrm{m}$ freestyle swimming performance. Journal of Human Sciences, 2017; 14(4): 3950-3955.

10. Guex K, Daucourt C, Borloz S. Validity and reliability of maximal-strength assessment of knee flexors and extensors using elastic bands. Journal of Sport Rehabilitation, 2015; 24(2): 151-155.

11. Hiratani T, David L, Costill L. Dry-land reistance training for competitive swimming. Medicine and Science in Sports and Exercise,1993; 25(8): 952-959.

12. Hostler D, Schwirian CI, Campos G, Toma K, Crill MT, Hagerman GR, Hagerman FC, Staron RS. Skeletal muscle adaptations in elastic resistance-trained young men and women. European Journal of Applied Physiology, 2001; 86(2): 112-118.

13. Iversen VM, Mork PJ, Vasseljen O, Bergquist R, Fimland MS. Multiple-joint exercises using elastic resistance bands vs. conventional resistance-training equipment: A crossover study. European Journal of Sport Science, 2017; 17(8): 973-982.

14. Karakuş M, Çelenk Ç, Kaya M, Sucan S, Turna B, Karakuş M. Çocuklarda 12 haftalık yüzme egzersizinin bazı fiziksel fizyolojik parametrelere etkisi. Akdeniz Spor Bilimleri Dergisi, 2018; 1(1): 50-57.

15. Kılınç H, Günay M, Kaplan Ş, Bayrakdar A. 7-12 yaş arası çocuklarda yüzme egzersizi ve thera-band çalışmalarının 
dinamik ve statik dengeye etkisinin incelenmesi. Journal of Human Sciences, 2018; 15(3): 1443-1452.

16. Maglischo EW. Swimming Fastest, Sprinterlerin Antrenmanları, çev. Yararcan M. İstanbul, 2018.

17. Mikesky AE, Topp R, Wigglesworth JK, Harsha DM, Edwards JE. Efficacy of a homebased training program for older adults using elastic tubing. European Journal of Applied Physiology and Occupational Physiology,1994; 69(4): 316-320.

18. Morouço PG, Marinho DA, Amaro NM, Peréz-Turpin JA, Marques MC. Effects of dry-land strength training on swimming performance: A brief review. Journal of Human Sport and Exercise, 2012; 7(2): 553-559.

19. Ostojyc SM, Mazic S, Dikic N. Profiling in basketball: Physical and physiological characteristics of elite players. Journal of Strength and Conditioning Research, 2006; 20(4): 740-744.

20. Page P. Ellenbecker T. Strenght Band Training. Human Kinetic, Champaing IL: 2005: 3-91.

21. Pion J, Fransen J, Deprez D, Segers V, Vaeyens R, Philippaerts $\mathrm{RM}$, Lenoir M. Stature and jumping height are required in female volleyball, but motor coordination is a key factor for future elite success. Journal of Strength Conditioning and Research, 2015; 29(6): 1480-1485.

22. Rosania JR. Weight Training, Not Your Grandma's Workout. Swimming Technique, 2004; 41(1): 17-20.

23. Salo D, Riewald AS. Complete conditioning for Swimming, Human Kinetics, Champaing IL: 2008: 198-199.

24. Santana JC. Strength training for swimmers: Training the core. Strength and Conditioning Journal, 2005; 27(2): 40-42.

25. Selçuk H, Karacan S. 11-13 yaş grubu erkek yüzme sporcularında 12 haftalık terabant antrenmanının yüzme performansına etkileri. Journal of Human Sciences, 2017; 14(4): 4958-4968.

26. Şenol M, Gülmez İ. Fonksiyonel egzersiz bandı (TRX) ve vücut ağırlığı kullanılarak uygulanan direnç antrenmanlarının yüzme performansına etkisi. İstanbul Üniversitesi Spor Bilimleri Dergisi, 2017; 7(1): 1303-1414.

27. Vandorpe B, Vandendriessche JB, Vaeyens R, Pion J, Lefevre J, Philippaerts RM, Lenoir M. The Value of a non-sportspecific motor test battery in predicting performance in young female gymnasts. Journal of Sports Sciences, 2012; 30(5): 497-505.

28. Watanebe M, Takai S. Age-related change of the factors affecting swimming performence in junior swimmers. Japanese Journal of Physical Fitness and Sport Medicine, 2005; 54(5): 353-361.

29. Yapıcı A, Maden B, Fındıkoğlu G. The effect of a 6-week land and resistance training of 13-16 years old swimmers groups to lower limb isokinetic strength values and to swimming performance. Journal of Human Sciences, 2016; 13(3): 52695281. 